\title{
Predictive efficacy
}

\section{of neutrophil-to-lymphocyte ratio for long-term prognosis in new onset acute coronary syndrome: a retrospective cohort study}

\author{
Yi Yang ${ }^{1+}$, Yanan $\mathrm{Xu}^{2+}$, Jun Wang ${ }^{2 \dagger}$, Xueqin Zhai $^{1}$ and Haibing Jiang ${ }^{1 *}$
}

\begin{abstract}
Background: Inflammation is involved in the pathogenesis and progression of coronary artery diseases (CADs), including acute coronary syndrome. The neutrophil-to-lymphocyte ratio (NLR) has been identified as a novel marker of the pro-inflammatory state. We aimed to evaluate the predictive efficacy of the NLR for the prognosis of patients with new-onset ACS.
\end{abstract}

Methods: We retrospectively included consecutive patients with new-onset ACS treated with emergency coronary angiography. NLR was measured at baseline and analyzed by tertiles. The severity of coronary lesions was evaluated by the Gensini score. Correlations of NLR with the severity of CAD and the incidence of major adverse cardiovascular diseases (MACEs) during follow-up were determined.

Results: Overall, 737 patients were included. The NLR was positively correlated with the severity of coronary lesions as assessed by Gensini score $(P<0.05)$. During the follow-up period (mean, $43.49 \pm 23.97$ months), 65 MACEs occurred. No significant association was detected between baseline NLR and the risk of MACEs during follow-up by either Kaplan-Meier or Cox regression analysis. Multivariable logistic regression analysis showed that a higher NLR was independently associated with coronary lesion severity as measured by the Gensini score (1st tertile vs. 3rd tertile hazard ratio [HR]: $0.527, P<0.001$, and 2 nd tertile vs. 3rd tertile HR: $0.474, P=0.025$ ).

Conclusions: The NLR may be associated with coronary disease severity at baseline but is not associated with adverse outcomes in patients with new-onset ACS.

Ethics Approval Number: 2019XE0208

Keywords: Acute coronary syndrome, Gensini score, Neutrophil and lymphocyte ratio, Major adverse cardiovascular events

\footnotetext{
*Correspondence: 15545959@qq.com

${ }^{\dagger}$ Yi Yang, Yanan Xu and Jun Wang these authors contributed to the work equally and should be regarded as co-first authors

${ }^{1}$ Department of Cardiology Fourth Ward, The Xinjiang Medical University Affiliated Hospital of Traditional Chinese Medicine, Urumqi 830011, China Full list of author information is available at the end of the article
}

\begin{abstract}
Background
The current understanding of the pathogenesis of atherosclerosis is focused on the "inflammatory hypothesis of atherothrombosis" theory $[1,2]$. Inflammatory cells and inflammatory signaling pathways play complex roles in the process of atherosclerosis, including initiating repair after vascular injury and mediating plaque instability and rupture, finally leading to acute coronary events [3-6].
\end{abstract}

(c) The Author(s) 2020. Open Access This article is licensed under a Creative Commons Attribution 4.0 International License, which permits use, sharing, adaptation, distribution and reproduction in any medium or format, as long as you give appropriate credit to the original author(s) and the source, provide a link to the Creative Commons licence, and indicate if changes were made. The images or other third party material in this article are included in the article's Creative Commons licence, unless indicated otherwise in a credit line to the material. If material is not included in the article's Creative Commons licence and your intended use is not permitted by statutory regulation or exceeds the permitted use, you will need to obtain permission directly from the copyright holder. To view a copy of this licence, visit http://creativecommons.org/licenses/by/4.0/. The Creative Commons Public Domain Dedication waiver (http://creativeco mmons.org/publicdomain/zero/1.0/) applies to the data made available in this article, unless otherwise stated in a credit line to the data. 
Patients with acute coronary syndrome (ACS), particularly those with new-onset ACS, often have an unstable clinical status and a poor prognosis, and optimization of risk stratification is clinically important in this patient group $[7,8]$.

Pathological studies have confirmed an increase in white blood cell mobilization in necrotic areas of the myocardium [9]. Moreover, white blood cell count, a clinical marker of universal inflammation, was shown to be independently associated with the risk of mortality and incidence of major adverse cardiovascular events (MACEs) in ACS patients [10, 11]. However, white blood cell count is unstable and tends to be affected by comorbidities such as infection. Interesting, it has also been indicated that decreased lymphocyte numbers may be associated with acute coronary events [12]. Recent studies showed that the neutrophil-to-lymphocyte ratio (NLR), which incorporates two major subgroups of white blood cells, may confer prognostic efficacy in many diseases, including inflammatory diseases, cardiovascular diseases, and malignancies [13, 14]. It has been suggested that an elevated NLR is associated with increased longterm mortality in patients with acute myocardial infarction (AMI) complicated by left main-and/or three-vessel disease [15]. Moreover, the role of the NLR for the management of patients with coronary artery disease (CAD) has also been evaluated, and the results showed that the NLR is correlated with CAD severity [16-18]. However, these studies were of limited scale and patients with a previous diagnosis of CAD were not excluded. Overall, clinical and experimental data support an important role for inflammation in CAD $[1,2]$.

Whether the NLR remains a significant prognostic factor after control for the severity of coronary lesions in new-onset ACS remains to be determined. Therefore, in this study, we retrospectively enrolled patients with newonset ACS to comprehensively evaluate the potential prognostic role of the NLR in these patients.

\section{Methods}

\section{Patients and study design}

Consecutive patients with a first diagnosis of ACS who were admitted to the Xinjiang Uygur Autonomous Region Traditional Chinese Medicine Hospital affiliated to the Xinjiang Medical University from January 2011 to January 2019 were included. ACS was diagnosed in accordance with previously established guidelines [19]. Patients with the following clinical conditions that may affect the NLR were excluded: hepatic or renal dysfunction, malignant tumors, acute infection, connective tissue disease, physical and chemical damage, previously proven systemic inflammatory disease, and recent surgery. Moreover, patients with a previous diagnosis of
CAD were also excluded. The protocol of the study was approved by the ethics committee of our local institution before enrollment of the patients. Informed patient consent was not needed due to the retrospective design of the study.

\section{Blood sampling and definitions of CAD risk factors}

Venous blood samples were taken when patients initially presented to the emergency department or prior to angiography, and the samples were sent immediately for laboratory analysis. Hypertension was defined if the patient was taking any antihypertensive medications or had blood pressure measurements over $140 / 90 \mathrm{mmHg}$ on least two separate occasions [20]. Diabetes was diagnosed based on medical history or measurements of fasting and/or postprandial glucose according to previous guidelines [21]. The estimated glomerular filtration rate (eGFR) was calculated with the Modification of Diet in Renal Diseases equation [22].

\section{Coronary angiography and Gensini score}

All patients underwent coronary angiography within $12 \mathrm{~h}$ of admission. Two independent investigators assessed the degrees of stenosis of the coronary lesions. Consensus with a third investigator was indicated if disagreement occurred. The Gensini score (GS), which incorporates both the extent of luminal narrowing and the geographic importance of the lesion, was calculated to reflect the severity of coronary lesions [23]. We used the GS instead of the SYNTAX system to reflect the severity of coronary lesions, because the calculation method of SYNTAX integral is more complicated. This limits its use in clinical practice and makes it difficult to apply to emergency patients, such as those with new-onset ACS. Moreover, research has shown that the SYNTAX score cannot be utilized to define future risk as the Gensini score can in patients with non-obstructive CAD [24].

\section{Outcomes}

Patients were followed by telephone interview or clinic visit. The primary outcome was all-cause mortality. The secondary outcome was a composite of MACEs, including cardiac mortality, non-fatal myocardial infarction and stroke, stent thrombosis, and revascularization (unplanned repeat PCI).

\section{Statistical analysis}

Continuous variables were expressed as mean and standard deviation (SD) or median and interquartile range (IQR), whereas categorical variables were presented as percentages. Patients were grouped according the tertiles of the NLR or GS. One-way analysis of variance (ANOVA) was used to evaluate the difference in normally 
distributed numeric variables among the groups, while for the non-normally distributed variables, Mann-Whitney U test or Kruskal-Wallis variance analysis was used. For the categorical variables, a chi-square $\left(x^{2}\right)$ test was employed. Linear regression analysis was performed to identify the factors associated with the GS. Prognostic factors for the occurrence of mortality and MACEs were analyzed with Kaplan-Meier survival method. Univariate analysis was first performed, and then significant variables were included in the multivariate Cox analysis. A $P$ value $<0.05$ indicated a statistically significant difference. All analyses were performed using SPSS 22.0 (SPSS Inc, Chicago, IL, USA).

\section{Results}

\section{Characteristics of patients according to NLR}

A flow chart outlining patient enrollment is shown in Fig. 1. A total of 737 patients with new on-set ACS were included. The baseline characteristics of the included patients according to the tertiles of NLR are shown in Table 1.The results showed that patients with a higher NLR were more likely to have dyslipidemia and ST-elevation myocardial infarction (STEMI; both $P<0.05$ ).
Incidence of mortality and MACEs according to the NLR

The incidences of clinical outcomes during follow-up (mean, $43.49 \pm 23.97$ months) for the included patients with new-onset ACS according to the NLR are shown in Table 2. No significant differences in the incidences of all-cause mortality, overall and components of MACEs, or bleeding events were detected among the three groups (all $\mathrm{P} \geq 0.05$ ).

\section{Characteristics of patients according to GS}

The baseline characteristics of patients according to the tertiles of GS (1st tertile $\mathrm{GS}<49 ; \mathrm{n}=250$, 2nd tertile GS: $49 \sim 85 ; \mathrm{n}=246$, and 3rd tertile GS $>85$; $\mathrm{n}=241$ ) are shown in Table 3 . The percentage of male patients, age, prevalence of diabetes mellitus, and history of smoking differed significantly among the groups according to GS tertile (all $P<0.05$ ). However, we found no relationship between other indicators and coronary severity (all $P>0.05$ ).

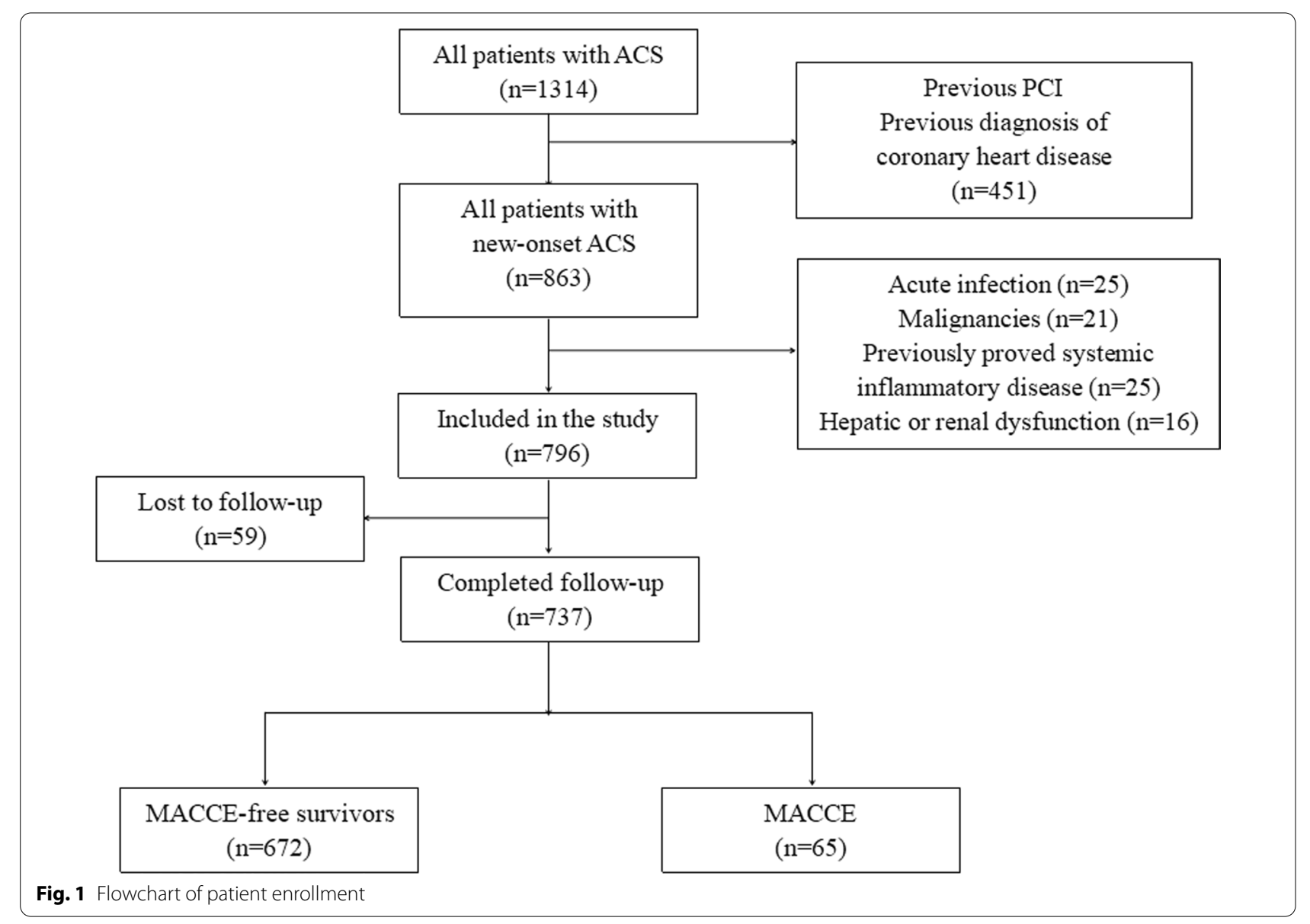


Table 1 Baseline characteristics of the included patients according to NLR tertiles

\begin{tabular}{|c|c|c|c|c|c|}
\hline & 1 st tertile $\leq 3.37(n=245)$ & $\begin{array}{l}\text { 2nd tertile } 3.38- \\
6.93(n=245)\end{array}$ & 3rd tertile $\geq 6.94(n=247)$ & $t / Z / X^{2}$ & $\underline{\mathbf{P}}$ \\
\hline Sex (male/female) & $200 / 45$ & $203 / 42$ & $213 / 34$ & 2.039 & 0.361 \\
\hline Age (years) & $58.20 \pm 12.46$ & $57.20 \pm 12.45$ & $58.64 \pm 12.04$ & 0.877 & 0.417 \\
\hline Hypertension & $113(46.1)$ & $115(46.9)$ & $103(41.7)$ & 1.582 & 0.453 \\
\hline Diabetes mellitus & $76(31.0)$ & $64(26.1)$ & $53(21.5)$ & 5.820 & 0.054 \\
\hline DM treatment & & & & 3.808 & 0.433 \\
\hline Diet only & $4(6.6)$ & $2(3.6)$ & $2(4.9)$ & & \\
\hline Oral hypoglycemic drugs & $23(37.7)$ & $30(54.5)$ & $21(51.2)$ & & \\
\hline Insulin & $34(55.7)$ & $23(41.8)$ & $18(43.9)$ & & \\
\hline Smoking & & & & 9.319 & 0.054 \\
\hline Never smoker & $110(44.9)$ & $132(53.9)$ & $115(46.6)$ & & \\
\hline Former smoker & $19(7.8)$ & $7(2.9)$ & $11(4.5)$ & & \\
\hline Current smoker & $116(47.3)$ & $106(43.3)$ & $121(49.0)$ & & \\
\hline Alcohol drinking & & & & 2.390 & 0.664 \\
\hline Never drinking & $151(61.9)$ & $149(61.3)$ & $146(59.3)$ & & \\
\hline Former drinking & $35(14.3)$ & $35(14.4)$ & $46(18.7)$ & & \\
\hline Current drinking & $58(23.8)$ & $59(24.3)$ & $54(22.0)$ & & \\
\hline Family history of CAD & $99(40.4)$ & $101(41.2)$ & $97(39.3)$ & 0.197 & 0.906 \\
\hline $\mathrm{SBP}(\mathrm{mmHg})$ & $122.02 \pm 20.97$ & $122.91 \pm 19.32$ & $122.21 \pm 19.17$ & 0.137 & 0.872 \\
\hline $\mathrm{DBP}(\mathrm{mmHg})$ & $75.96 \pm 13.59$ & $76.75 \pm 12.90$ & $77.23 \pm 13.84$ & 0.567 & 0.567 \\
\hline Heart rate (bpm) & $82.78 \pm 15.31$ & $80.54 \pm 14.71$ & $82.50 \pm 15.03$ & 1.618 & 0.199 \\
\hline $\mathrm{BMI}\left(\mathrm{kg} / \mathrm{m}^{2}\right)$ & $25.11 \pm 5.28$ & $25.04 \pm 5.15$ & $24.63 \pm 5.94$ & 0.475 & 0.622 \\
\hline $\mathrm{HDL}-\mathrm{C}(\mathrm{mmol} / \mathrm{l})$ & $0.95 \pm 0.26$ & $1.00 \pm 0.26$ & $1.01 \pm 0.26$ & 2.575 & 0.077 \\
\hline LDL-C (mmol/l) & $2.93 \pm 0.91$ & $2.96 \pm 0.84$ & $2.97 \pm 0.85$ & 0.095 & 0.910 \\
\hline $\mathrm{TC}(\mathrm{mmol} / \mathrm{l})$ & $4.61 \pm 1.22$ & $4.66 \pm 1.26$ & $4.59 \pm 1.08$ & 0.181 & 0.834 \\
\hline TG (mmol/l) & $1.76 \pm 1.13$ & $2.04 \pm 1.06^{\mathrm{a}}$ & $2.26 \pm 1.17^{\mathrm{ab}}$ & 11.988 & $<0.001$ \\
\hline ApoA1 (g/L) & $1.21 \pm 0.29$ & $1.28 \pm 0.53$ & $1.22 \pm 0.27$ & 1.604 & 0.202 \\
\hline ApoB (g/L) & $0.92 \pm 0.49$ & $0.90 \pm 0.27$ & $0.91 \pm 0.26$ & 0.160 & 0.852 \\
\hline Lp (a) (g/L) & $244.88 \pm 258.72$ & $236.56 \pm 227$ & $239.63 \pm 214.2$ & 0.059 & 0.942 \\
\hline Creatinine (mmol/L) & $79.27 \pm 36.5$ & $81.75 \pm 56.31$ & $79.25 \pm 35.77$ & 0.259 & 0.772 \\
\hline $\mathrm{BUN}(\mathrm{mmol} / \mathrm{l})$ & $5.42 \pm 2.76$ & $5.69 \pm 2.26$ & $5.68 \pm 2.81$ & 0.833 & 0.435 \\
\hline Uric acid (mmol/L) & $334.27 \pm 90.96$ & $326.4 \pm 88.92$ & $325.73 \pm 99.45$ & 0.629 & 0.534 \\
\hline WBC & $9.03 \pm 3.21$ & $11.05 \pm 3.35^{\mathrm{a}}$ & $12.32 \pm 3.41^{\mathrm{ab}}$ & 61.212 & $<0.001$ \\
\hline Monocyte count & $0.63 \pm 0.24$ & $0.66 \pm 0.34$ & $0.46 \pm 0.32^{\mathrm{ab}}$ & 30.768 & $<0.001$ \\
\hline PLR & $89.94 \pm 36.52$ & $145.34 \pm 110.94^{\mathrm{a}}$ & $265.13 \pm 175.65^{\mathrm{ab}}$ & 132.705 & $<0.001$ \\
\hline RBC & $4.77 \pm 0.72$ & $4.85 \pm 0.58$ & $4.65 \pm 0.82^{b}$ & 4.852 & 0.008 \\
\hline HGB & $145.04 \pm 22.16$ & $144.99 \pm 26.14$ & $142.53 \pm 28.78$ & 0.759 & 0.468 \\
\hline PLT & $224.49 \pm 71.94$ & $229.48 \pm 144.24$ & $236.26 \pm 162.19$ & 0.492 & 0.612 \\
\hline MPV & $10.16 \pm 1.43$ & $10.26 \pm 1.24$ & $10.14 \pm 1.66$ & 0.499 & 0.608 \\
\hline PDW & $13.36 \pm 3.83$ & $13.43 \pm 3.71$ & $13.31 \pm 3.22$ & 0.065 & 0.937 \\
\hline PCT & $0.24 \pm 0.08$ & $0.23 \pm 0.09$ & $0.25 \pm 0.12$ & 1.632 & 0.196 \\
\hline Clinical diagnosis & & & & 20.160 & $<0.001$ \\
\hline UA & $52(21.2)$ & $29(11.8)$ & $19(7.7)$ & & \\
\hline NSTEMI & $26(10.7)$ & $30(12.2)$ & $31(12.6)$ & & \\
\hline STEMI & $167(68.2)$ & $186(75.9)$ & $197(79.8)$ & & \\
\hline \multicolumn{6}{|l|}{ Coronary artery lesion } \\
\hline UPLMT & $22(9.2)$ & 25 (10.6) & $21(8.7)$ & 0.526 & 0.769 \\
\hline LAD & $217(88.9)$ & $211(86.5)$ & $216(87.8)$ & 0.687 & 0.709 \\
\hline LCX & $155(64.3)$ & $147(61.0)$ & $155(63.0)$ & 0.577 & 0.749 \\
\hline RCA & $179(74.0)$ & $178(73.3)$ & $186(75.3)$ & 0.278 & 0.870 \\
\hline
\end{tabular}


Table 1 (continued)

\begin{tabular}{|c|c|c|c|c|c|}
\hline & 1 st tertile $\leq 3.37(n=245)$ & $\begin{array}{l}\text { 2nd tertile 3.38- } \\
6.93(n=245)\end{array}$ & 3 rd tertile $\geq 6.94(n=247)$ & $t / Z / X^{2}$ & $\underline{\mathbf{P}}$ \\
\hline \multicolumn{6}{|c|}{ Medication situation } \\
\hline Aspirin & $20(8.2)$ & $32(13.1)$ & $22(8.9)$ & 3.782 & 0.151 \\
\hline Statins & $18(7.3)$ & $28(11.4)$ & $21(8.5)$ & 2.625 & 0.269 \\
\hline$\beta$-Blockers & $16(6.5)$ & $16(6.5)$ & $12(4.9)$ & 0.818 & 0.664 \\
\hline ACEI/ARB & $8(3.3)$ & $13(5.3)$ & $6(2.4)$ & 3.049 & 0.218 \\
\hline $\mathrm{CCB}$ & $41(16.7)$ & $26(10.6)$ & $35(14.2)$ & 3.885 & 0.143 \\
\hline
\end{tabular}

a $P<0.05$ compared to the 1 st tertile; ${ }^{\mathrm{b} P}<0.05$ compared to the 2 nd tertile

Table 2 Incidence of adverse outcomes in ACS patients according to the NLR tertiles

\begin{tabular}{|c|c|c|c|c|c|}
\hline & $\begin{array}{l}1 \text { st tertile } \leq 3.37 \\
(n=245)\end{array}$ & $\begin{array}{l}\text { 2nd tertile 3.38-6.93 } \\
(n=245)\end{array}$ & $\begin{array}{l}\text { 3rd tertile } \geq 6.94 \\
(n=247)\end{array}$ & $x^{2}$ & $\underline{\mathbf{P}}$ \\
\hline ACM, n (\%) & $5(2.0)$ & $12(4.9)$ & $7(2.8)$ & 3.385 & 0.184 \\
\hline Non-sudden cardiac death, n (\%) & $1(0.4)$ & $0(0.0)$ & $0(0.0)$ & 1.825 & 0.665 \\
\hline MACE, n (\%) & $21(8.6)$ & $24(9.8)$ & $20(8.1)$ & 0.469 & 0.791 \\
\hline$C M, n(\%)$ & $4(1.6)$ & $12(4.9)$ & $7(2.8)$ & 4.421 & 0.110 \\
\hline Re-myocardial infarction, n (\%) & $4(1.6)$ & $0(0.0)$ & $2(0.8)$ & 5.578 & 0.061 \\
\hline $\mathrm{ST}, \mathrm{n}(\%)$ & $0(0.0)$ & $0(0.0)$ & $2(0.8)$ & 2.617 & 0.332 \\
\hline Revascularization, n (\%) & $11(4.5)$ & $17(6.9)$ & $12(4.9)$ & 1.666 & 0.435 \\
\hline Stroke, n (\%) & $1(0.4)$ & $0(0.0)$ & $2(0.8)$ & 2.764 & 0.251 \\
\hline Bleeding events, n (\%) & $1(0.4)$ & $6(2.4)$ & $1(0.4)$ & 5.904 & 0.052 \\
\hline
\end{tabular}

\section{Factors associated with coronary lesion severity} as detected by Gensini Score

The results of multivariable logistic regression analysis showed that a higher NLR was independently associated with coronary lesion severity as measured by the GS (1st tertile vs. 3rd tertile hazard ratio [HR]: $0.527, P<0.001$, and 2 nd tertile vs. 3rd tertile HR: $0.474, P=0.025)$. The other factors independently related to GS included advanced age (HR: 1.033, $P<0.001)$, male gender (HR: $1.835, P<0.001$ ), and the absence of diabetes (HR: 0.507, $P<0.001$; Table 4).

\section{Predictors of clinical outcomes}

Overall, 65 patients experienced MACEs during followup, including $23(35.38 \%)$ cases of cardiac mortality, 6 (9.23\%) cases of nonfatal MI, $2(3.08 \%)$ cases of ST, 33 (50.77\%) cases of revascularization, and three (4.62\%) cases of nonfatal stroke. The NLR was not correlated with MACEs either as a continuous variable or according to tertiles (both $P>0.05$ ). Kaplan-Meier analysis did not show a significant difference in the event-free survival rate among the NLR tertiles $(P<0.775$, Fig. 2$)$. The results of univariable Cox regression analysis showed that age, systolic blood pressure, diastolic blood pressure, red blood cell count, left main coronary stenosis, stenosis of the right coronary artery, and high GS were predictors of
MACEs (Table 5, all $P<0.05$ ). Kaplan-Meier analysis also demonstrated that the risks of MACEs differed significantly different among the groups of different GS tertiles $(P<0.001)$. Multivariate Cox-regression analysis showed that age (HR: 1.049, 95\% confidence interval [CI]: 1.024$1.075, P<0.001$ ), systolic blood pressure (HR: $1.029,95 \%$ CI: $1.009-1.049, P=0.005)$, and tertile of GS (3rd tertile vs. 1 st tertile, HR: $3.216,95 \% \mathrm{CI}: 1.458-7.093, P=0.004)$ were independent risk factors for MACEs.

\section{Discussion}

The results of this retrospective cohort study showed that, although a higher NLR at baseline was independently associated with the severity of coronary lesions in new-onset ACS patients as evidenced by GS, the NLR was not a predictor of adverse clinical outcome during follow-up. We found that advanced age, elevated systolic $\mathrm{BP}$, and higher GS are potential independent predictors of poor outcomes. Taken together, our results do not support incorporation of baseline NLR as a prognostic factor for new-onset ACS patients.

The key pathophysiologic processes for ACS include the rupture of a vulnerable plaque and subsequent formation of thrombosis $[25,26]$, and the role of inflammation in these processes has not only been confirmed by pathological studies, but also shown in some optical 
Table 3 Baseline characteristics of the included patients according to the GS tertiles

\begin{tabular}{|c|c|c|c|c|c|}
\hline & 1 st tertile $\leq 45(n=250)$ & 2nd tertile 49-85 $(n=246)$ & $3 r d$ tertile $\geq 85(n=241)$ & $t / Z / X^{2}$ & $\underline{P}$ \\
\hline Sex (male/female) & $171 / 79$ & $191 / 55$ & $200 / 41$ & 14.814 & 0.001 \\
\hline Age (years) & $55.37 \pm 12.26$ & $58.23 \pm 11.84^{\mathrm{a}}$ & $60.53 \pm 12.34^{\mathrm{ab}}$ & 11.111 & $<0.001$ \\
\hline Hypertension & $106(42.4)$ & $111(45.1)$ & $114(47.3)$ & 1.199 & 0.549 \\
\hline Diabetes mellitus & $45(18.0)$ & $66(26.8)$ & $82(34.0)^{a b}$ & 16.381 & $<0.001$ \\
\hline Diabetes mellitus treatment & & & & 0.846 & 0.932 \\
\hline Diet only & $2(4.2)$ & $3(6.7)$ & $3(4.7)$ & & \\
\hline Oral hypoglycemic drugs & $23(47.9)$ & $19(42.2)$ & $32(50.0)$ & & \\
\hline Insulin & $23(47.9)$ & $23(51.1)$ & $29(45.3)$ & & \\
\hline Smoking & & & & 9.963 & 0.041 \\
\hline Never smoker & $134(53.6)$ & $119(48.4)$ & $104(43.2)$ & & \\
\hline Former smoker & $16(6.4)$ & $13(5.3)$ & $8(3.3)$ & & \\
\hline Current smoker & $100(40.0)$ & $114(46.3)$ & $129(53.5)$ & & \\
\hline Alcohol drinking & & & & 1.053 & 0.902 \\
\hline Never drinking & $147(58.8)$ & $153(63.2)$ & $146(60.6)$ & & \\
\hline Former drinking & $41(16.4)$ & $36(14.9)$ & $39(16.2)$ & & \\
\hline Current drinking & $62(24.8)$ & $53(21.9)$ & $56(23.2)$ & & \\
\hline Family history of CAD & $95(38.0)$ & $100(40.7)$ & $102(42.3)$ & 0.972 & 0.615 \\
\hline $\mathrm{SBP}(\mathrm{mmHg})$ & $123.72 \pm 20.64$ & $122.37 \pm 18.87$ & $121 \pm 19.85$ & 1.157 & 0.315 \\
\hline $\mathrm{DBP}(\mathrm{mmHg})$ & $76.86 \pm 13.88$ & $77.45 \pm 13.12$ & $75.62 \pm 13.3$ & 1.174 & 0.310 \\
\hline Heart rate & $80.42 \pm 14.05$ & $81.78 \pm 14.26$ & $83.68 \pm 16.58$ & 2.930 & 0.054 \\
\hline BMI $\left(\mathrm{kg} / \mathrm{m}^{2}\right)$ & $24.78 \pm 5.95$ & $24.9 \pm 5.05$ & $25.11 \pm 5.36$ & 0.203 & 0.817 \\
\hline $\mathrm{HDL}-\mathrm{C}(\mathrm{mmol} / \mathrm{l})$ & $0.96 \pm 0.23$ & $0.99 \pm 0.26$ & $1.01 \pm 0.28$ & 2.152 & 0.117 \\
\hline LDL-C (mmol/l) & $2.88 \pm 0.85$ & $2.94 \pm 0.74$ & $3.04 \pm 1$ & 1.434 & 0.239 \\
\hline $\mathrm{TC}(\mathrm{mmol} / \mathrm{l})$ & $4.63 \pm 1.23$ & $4.57 \pm 0.98$ & $4.68 \pm 1.34$ & 0.374 & 0.688 \\
\hline TG (mmol/l) & $2.14 \pm 2.15$ & $2.15 \pm 2.13$ & $1.98 \pm 1.45$ & 0.426 & 0.653 \\
\hline ApoA1 (g/L) & $1.2 \pm 0.26$ & $1.23 \pm 0.3$ & $1.29 \pm 0.53$ & 2.710 & 0.067 \\
\hline ApoB (g/L) & $0.9 \pm 0.27$ & $0.88 \pm 0.23$ & $0.96 \pm 0.52$ & 2.433 & 0.089 \\
\hline Lp(a) (g/L) & $234.48 \pm 232.84$ & $263.47 \pm 280.29$ & $222 \pm 172.39$ & 1.505 & 0.223 \\
\hline $\mathrm{Cr}(\mathrm{mmol} / \mathrm{L})$ & $80.9 \pm 35.25$ & $80.52 \pm 42.9$ & $78.84 \pm 52.29$ & 0.150 & 0.860 \\
\hline BUN (mmol/l) & $5.71 \pm 2.91$ & $5.59 \pm 2.87$ & $5.5 \pm 1.95$ & 0.394 & 0.674 \\
\hline Uric acid ( $\mu \mathrm{mol} / \mathrm{L})$ & $326.22 \pm 92.64$ & $335.89 \pm 94.27$ & $324.19 \pm 92.59$ & 1.090 & 0.337 \\
\hline WBC & $10.88 \pm 3.74$ & $10.87 \pm 3.71$ & $10.64 \pm 3.29$ & 0.339 & 0.712 \\
\hline Neutrophil count & $8.13 \pm 3.63$ & $8.37 \pm 3.58$ & $8.11 \pm 3.15$ & 0.419 & 0.658 \\
\hline lymphocyte count & $1.95 \pm 1.27$ & $1.76 \pm 0.96$ & $1.81 \pm 1.07$ & 1.954 & 0.142 \\
\hline NLR & $5.24 \pm 3.90$ & $6.41 \pm 5.24$ & $7.46 \pm 5.51$ & 12.506 & $<0.001$ \\
\hline NLR tertiles & & & & 19.287 & 0.001 \\
\hline 1st tertile & $104(41.6)$ & $77(31.3)$ & $64(26.6)$ & & \\
\hline 2nd tertile & $84(33.6)$ & $84(34.1)$ & $77(32.0)$ & & \\
\hline 3rd tertile & $62(24.8)$ & $85(34.6)$ & $100(41.5)$ & & \\
\hline Monocyte count & $0.59 \pm 0.32$ & $0.58 \pm 0.32$ & $0.57 \pm 0.31$ & 0.258 & 0.773 \\
\hline PLR & $158.09 \pm 122.37$ & $176.51 \pm 159.31$ & $166.74 \pm 142.57$ & 1.042 & 0.353 \\
\hline RBC & $4.75 \pm 0.70$ & $4.74 \pm 0.73$ & $4.79 \pm 0.72$ & 0.399 & 0.672 \\
\hline $\mathrm{HGB}$ & $145.15 \pm 24.97$ & $142.77 \pm 27.85$ & $144.62 \pm 24.6$ & 0.579 & 0.561 \\
\hline PLT & $223.74 \pm 69.67$ & $242.01 \pm 203.23$ & $224.52 \pm 77.66$ & 1.508 & 0.222 \\
\hline MPV & $10.20 \pm 1.29$ & $10.16 \pm 1.75$ & $10.2 \pm 1.28$ & 0.065 & 0.937 \\
\hline PDW & $13.66 \pm 3.35$ & $13.44 \pm 3.78$ & $12.98 \pm 3.63$ & 2.298 & 0.101 \\
\hline PCT & $0.24 \pm 0.08$ & $0.24 \pm 0.11$ & $0.24 \pm 0.10$ & 0.239 & 0.788 \\
\hline Clinical diagnosis & & & & 1.672 & 0.796 \\
\hline UA & $38(15.2)$ & $32(13.0)$ & $30(12.4)$ & & \\
\hline
\end{tabular}


Table 3 (continued)

\begin{tabular}{|c|c|c|c|c|c|}
\hline & 1 st tertile $\leq 45(n=250)$ & 2nd tertile 49-85 $(n=246)$ & $3 r d$ tertile $\geq 85(n=241)$ & $t / Z / X^{2}$ & $\underline{\mathbf{P}}$ \\
\hline NSTEMI & $32(12.8)$ & $26(10.6)$ & $29(12.0)$ & & \\
\hline STEMI & $180(72.0)$ & $188(76.4)$ & $182(75.5)$ & & \\
\hline Aspirin & $18(7.2)$ & $23(9.3)$ & $33(13.7)$ & 5.923 & 0.052 \\
\hline Statins & $17(6.8)$ & $19(7.7)$ & $31(12.9)^{a b}$ & 6.029 & 0.043 \\
\hline$\beta$-Blockers & $15(6.0)$ & $12(4.9)$ & $17(7.1)$ & 1.027 & 0.598 \\
\hline ACEI/ARB & $7(2.8)$ & $8(3.3)$ & $12(5.0)$ & 1.828 & 0.401 \\
\hline CCB & $32(12.8)$ & $34(13.8)$ & $36(14.9)$ & 0.470 & 0.790 \\
\hline
\end{tabular}

Abbreviations are as in Table 1

Table 4 Factors independently correlated with the severity of coronary arterial atherosclerosis as detected by GS: multivariate logistic regression analysis

\begin{tabular}{|c|c|c|c|c|c|c|c|}
\hline \multirow[t]{2}{*}{ Variables } & \multirow[t]{2}{*}{ B } & \multirow[t]{2}{*}{ SE } & \multirow[t]{2}{*}{ Wald } & \multirow[t]{2}{*}{$\mathbf{P}$} & \multirow[t]{2}{*}{ HR } & \multicolumn{2}{|l|}{$95 \% \mathrm{Cl}$} \\
\hline & & & & & & Lower limit & Upper limit \\
\hline Age & 0.032 & 0.006 & 27.046 & $<0.001$ & 1.033 & 1.020 & 1.045 \\
\hline Sex (male vs female) & 0.607 & 0.173 & 12.363 & $<0.001$ & 1.835 & 1.309 & 2.575 \\
\hline Diabetes mellitus (No vs Yes) & -0.680 & 0.163 & 17.508 & $<0.001$ & 0.507 & 0.368 & 0.696 \\
\hline \multicolumn{8}{|l|}{ Smoking } \\
\hline Never smoker vs current drinking & -0.178 & 0.152 & 2.501 & 0.079 & 0.837 & 0.216 & 1.255 \\
\hline Former smoker vs current drinking & -0.237 & 0.171 & 3.390 & 0.059 & 0.790 & 0.310 & 1.098 \\
\hline Statins & -0.470 & 0.245 & 3.666 & 0.056 & 0.625 & 0.386 & 1.011 \\
\hline \multicolumn{8}{|l|}{ NLR group } \\
\hline 1st tertile vs 3rd tertile & -0.640 & 0.174 & 13.526 & $<0.001$ & 0.527 & 0.375 & 0.742 \\
\hline 2nd tertile vs 3rd tertile & -0.747 & 0.334 & 4.993 & 0.025 & 0.474 & 0.246 & 0.912 \\
\hline
\end{tabular}

$\mathrm{Cl}$, confidence interval; $\mathrm{HR}$, hazard ratio

coherence tomography-based studies [6, 27]. Therefore, it has been proposed that the NLR, a novel but easily obtained marker of inflammation, may be a prognostic factor for ACS patients. Indeed, some previous studies suggested a prognostic role for the NLR in CAD patients. In a recent study with 636 STEMI patients, the NLR was significantly associated with in-hospital mortality [28]. Moreover, a post-hoc analysis showed that the NLR is associated with increased long-term mortality in patients with acute myocardial infarction (AMI) complicated by left main- and/or three-vessel disease [15]. However, in our retrospective cohort study, we did not find a significant association between a high NLR and poor prognosis in these patients, despite the relatively longer follow-up duration in our study compared with previous studies. The mechanisms have yet to be fully determined. Previous studies showed that the NLR changes dramatically, with the maximal level seen during the occurrence of inflammatory-related events [29]. Because neutrophils have a short life span and faster turnover, it is better to observe neutrophils in a dynamic manner rather than in a single measurement. Moreover, our study had a longer follow-up duration than previous ones, which may indicate that the potential prognostic role of the NLR in ACS is only acute. The relationships of NLR with ACS, overall mortality, and cancer survival have generally been thought to be driven by chronic inflammation [ 1 , 2]. However, patients with a previous diagnosis of CAD were excluded in our study, and whether the NLR is associated with new-onset ACS has not been well established and remains incompletely understood. To the best of our knowledge, the potential link between NLR and new onset ACS has not been reported.

Another explanation is that the potential prognostic role of the NLR in ACS is confounded by factors related to the severity of coronary lesions, such as the GS. Therefore, the prognostic efficacy of the NLR is limited in a model that incorporates factors reflecting the severity of coronary lesions. Our results indicated that the NLR is significantly correlated with coronary lesion severity as evidenced by the GS. The results of our present study confirm the previous concept that inflammation correlates with the degree of coronary stenosis in CAD patients. Pathophysiologically, myocardial ischemia can induce an immediate rise in the plasma NLR, the magnitude of which is proportional 


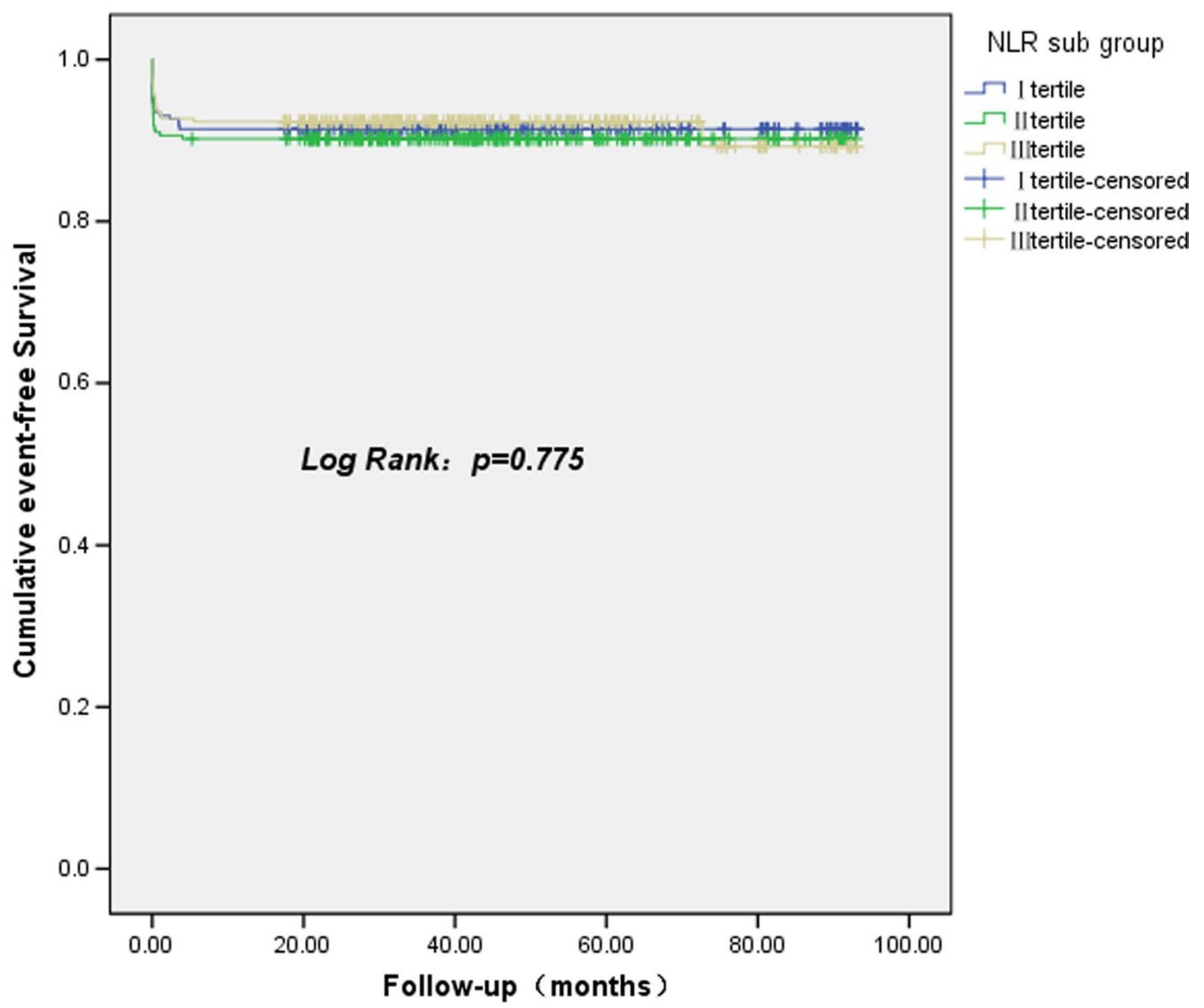

Fig. 2 Cumulative event-free survival analysis according to NLR tertiles

to the severity of ischemia, although the neutrophil half-life is short [30]. Subsequently, a state of stress and inflammation, as seen in ACS patients, could result in increased levels of inflammatory markers in the blood circulation, accompanied by increased blood cortisol levels. An increase in cortisol has been shown to induce apoptosis, which in turn leads to lymphopenia and even inversion of the CD4+/CD8 + T lymphocyte ratio [31]. Therefore, an elevated NLR represents an exaggerated inflammatory response that may reflect coronary atherosclerosis progression [16-18], and to some extent, may predict the acute prognosis in these patients $[15,32-$ 34]. On the other hand, medications such as statins are well known to have anti-inflammatory actions [35], and the common use of statins during the post-acute phase of ACS may also reduce the prognostic efficacy of the NLR for long-term outcomes in ACS patients. Xinjiang is characterized by the integration of diverse ethnic cultures, but people in Xinjiang generally do not have a deep understanding of cardiovascular disease. Accordingly, a low treatment rate and poor adherence are common problems of hypertension management in this area. Therefore, it appears that although approximately $50 \%$ of the patients had hypertension, only $3-15 \%$ of patients were receiving treatment with antihypertensive agents. We are working hard to actively promote popularization of the science of cardiovascular diseases in different forms and languages in this region.

\section{Study limitations}

First, as a retrospective observational single-center study with a small sample size, our study may be confounded by recall bias. Our results should be validated in prospective studies. Second, our study included consecutive patients with an initial diagnosis of ACS, and the diagnosis of the patients varied. Third, the NLR was only measured once at admission, and whether changes in the NLR during hospitalization or the NLR at discharge have an impact on the prognosis of these patients remains unknown. Finally, as the study was conducted over 8 years, PCI techniques and medical therapies likely evolved and changed with increasing evidence, which is likely to impact the outcome. 
Table 5 Predictors of the occurrence of MACEs in patients with new-onset ACS: results of univariate and multivariate Cox-regression analysesss

\begin{tabular}{|c|c|c|c|c|c|c|}
\hline \multirow[t]{2}{*}{ Variables } & \multicolumn{3}{|c|}{ Univariate } & \multicolumn{3}{|c|}{ Multivariate } \\
\hline & HR & $95 \% \mathrm{Cl}$ & $P$ & HR & $95 \% \mathrm{Cl}$ & $P$ \\
\hline Sex (Male/Female) & 1.275 & $0.694-2.342$ & 0.433 & & & \\
\hline Age & 1.051 & $1.029-1.073$ & $<0.001$ & 1.049 & $1.024-1.075$ & $<0.001$ \\
\hline Hypertension & 0.918 & $0.562-1.499$ & 0.731 & & & \\
\hline Diabetes mellitus & 1.175 & $0.676-2.044$ & 0.568 & & & \\
\hline \multicolumn{7}{|l|}{ Smoking } \\
\hline Former smoker vs never smoker & 1.177 & $0.161-8.616$ & 0.872 & & & \\
\hline Current smoker vs never smoker & 0.842 & $0.516-1.374$ & 0.490 & & & \\
\hline \multicolumn{7}{|l|}{ Alcohol drinking } \\
\hline Former smoker vs never drinking & 1.061 & $0.526-2.139$ & 0.868 & & & \\
\hline Current smoker vs never drinking & 1.390 & $0.797-2.423$ & 0.246 & & & \\
\hline Family history of CAD & 0.876 & $0.529-1.450$ & 0.605 & & & \\
\hline $\mathrm{SBP}(\mathrm{mmHg})$ & 1.029 & $1.016-1.042$ & $<0.001$ & 1.029 & $1.009-1.049$ & 0.005 \\
\hline $\mathrm{DBP}(\mathrm{mmHg})$ & 1.040 & $1.019-1.059$ & $<0.001$ & 1.007 & $0.978-1.038$ & 0.626 \\
\hline Heart rate & 1.008 & $0.992-1.024$ & 0.319 & & & \\
\hline $\mathrm{BMl}$ & 0.965 & $0.928-1.003$ & 0.072 & & & \\
\hline $\mathrm{HDL}-\mathrm{C}(\mathrm{mmol} / \mathrm{l})$ & 2.371 & $0.909-6.183$ & 0.078 & & & \\
\hline LDL-C (mmol/l) & 1.238 & $0.913-1.680$ & 0.169 & & & \\
\hline $\mathrm{TC}(\mathrm{mmol} / \mathrm{l})$ & 1.132 & $0.905-1.416$ & 0.278 & & & \\
\hline $\mathrm{TG}(\mathrm{mmol} / \mathrm{l})$ & 0.956 & $0.813-1.123$ & 0.583 & & & \\
\hline ApoA1 (g/L) & 1.170 & $0.662-2.067$ & 0.589 & & & \\
\hline ApoB (g/L) & 1.118 & $0.574-2.181$ & 0.742 & & & \\
\hline Lp(a) (g/L) & 0.999 & $0.997-1.001$ & 0.150 & & & \\
\hline Creatinine (mmol/L) & 1.001 & $0.994-1.006$ & 0.995 & & & \\
\hline BUN (mmol/l) & 0.978 & $0.881-1.086$ & 0.675 & & & \\
\hline Uric acid ( $\mu \mathrm{mol} / \mathrm{L})$ & 1.001 & $0.997-1.003$ & 0.980 & & & \\
\hline \multicolumn{7}{|l|}{ NLR group } \\
\hline 2nd tertile vs 1st tertile & 1.155 & $0.643-2.075$ & 0.629 & & & \\
\hline 3rd tertile vs 1st tertile & 0.940 & $0.509-1.734$ & 0.843 & & & \\
\hline Monocyte count & 0.923 & $0.427-1.996$ & 0.839 & & & \\
\hline PLR & 1.001 & $0.999-1.002$ & 0.080 & & & \\
\hline RBC & 1.534 & $1.015-2.318$ & 0.042 & 1.452 & $0.991-1.038$ & 0.056 \\
\hline HGB & 1.002 & $0.993-1.012$ & 0.660 & & & \\
\hline PLT & 1.001 & $0.999-1.002$ & 0.550 & & & \\
\hline MPV & 1.001 & $0.847-1.180$ & 0.997 & & & \\
\hline PDW & 0.946 & $0.882-1.016$ & 0.126 & & & \\
\hline РCT & 1.654 & $0.177-15.465$ & 0.659 & & & \\
\hline WBC & 0.979 & 0.913-1.049 & 0.540 & & & \\
\hline \multicolumn{7}{|l|}{ Clinical diagnosis } \\
\hline NSTEMI & 1.062 & $0.386-2.9222$ & 0.907 & & & \\
\hline STEMI & 0.862 & 0.3692 .012 & 0.731 & & & \\
\hline UPLMT & 2.446 & $1.301-4.599$ & 0.006 & 1.466 & $0.763-2.816$ & 0.251 \\
\hline LAD & 2.155 & $0.783-5.929$ & 0.137 & & & \\
\hline LCX & 1.430 & $0.836-2.445$ & 0.191 & & & \\
\hline RCA & 2.186 & $1.080-4.423$ & 0.030 & 1.242 & $0.598-2.579$ & 0.561 \\
\hline Aspirin & 1.085 & $0.495-2.377$ & 0.838 & & & \\
\hline Statins & 1.230 & $0.562-2.695$ & 0.605 & & & \\
\hline$\beta$-Blockers & 0.756 & $0.237-2.410$ & 0.637 & & & \\
\hline
\end{tabular}


Table 5 (continued)

\begin{tabular}{|c|c|c|c|c|c|c|}
\hline \multirow[t]{2}{*}{ Variables } & \multicolumn{3}{|c|}{ Univariate } & \multicolumn{3}{|c|}{ Multivariate } \\
\hline & HR & $95 \% \mathrm{Cl}$ & $P$ & HR & $95 \% \mathrm{Cl}$ & $P$ \\
\hline ACEI/ARB & 0.813 & $0.199-3.323$ & 0.773 & & & \\
\hline $\mathrm{CCB}$ & 0.866 & $0.413-1.815$ & 0.703 & & & \\
\hline $\mathrm{PCl}$ & 0.614 & $0.280-1.345$ & 0.223 & & & \\
\hline \multicolumn{7}{|l|}{ Gensini group } \\
\hline 2nd tertile vs 1st tertile & 2.631 & $1.159-5.973$ & 0.021 & 1.989 & $0.861-4.596$ & 0.107 \\
\hline 3 rd tertile vs 1 st tertile & 5.076 & $2.363-10.900$ & $<0.001$ & 3.216 & $1.458-7.093$ & 0.004 \\
\hline
\end{tabular}

\section{Conclusions}

The NLR may be associated with coronary lesion severity at baseline but is not associated with adverse outcomes in patients with new-onset ACS.

\section{Abbreviations}

BMI: Body mass index; SBP: Systolic blood pressure; DBP: Diastolic blood pressure; NLR: Neutrophil to lymphocyte ratio; WBC: White blood count; PLT: Platelet count; MPV: Mean platelet volume; PCT: Thrombocytocrit; PDW: Platelet distribution width; RBC: Red blood cell; HGB: Hemoglobin; BUN: Blood urea nitrogen; Cr: Creatinine; TC: Total cholesterol; TG: Triglyceride; HDL-C: High-density lipoprotein cholesterol; LDL-c: Low-density lipoprotein-cholesterol; Apo-Al: Apolipoprotein A1; Apo-B: Apolipoprotein B; Lp(a): Lipoprotein (a); CCB: Calcium channel blocker; ACEl: Angiotensin-converting enzyme inhibitor; ARB: Angiotensin receptor blocker; CAD: Coronary artery disease; LAD: Left anterior descending artery; LCX: Left circumflex artery; RCA: Right coronary artery; UA: Unstable angina; NSTEMI: Non-ST-segment elevation myocardial infarction; STEMI: ST-segment elevation myocardial infarction; ACM: All-cause mortality; CM: Cardiac mortality; MACE: Major adverse cardiovascular events; ST: Stent thrombosis; PCI: Percutaneous transluminal coronary intervention; Cl: Confidence interval; HR: Hazard ratio.

\section{Acknowledgements}

Thanks to everyone for supporting our final study.

\section{Authors' contributions}

Conceived and designed the study: HJ. Data collection and analyzed the data. JW and $X Z$ Quality control the study and revision:JW and YX. Wrote the paper: YY. YY;YX and JW contributed to the work equally and should be regarded as co-first authors. All authors read and approved the final manuscript.

\section{Funding}

None.

\section{Availability of data and materials}

The data that support the findings of this study are available from the Xinjiang Medical University Affiliated Hospital of Traditional Chinese Medicine. But restrictions apply to the availability of these data, which were used under license for the current study, and so are not publicly available. Data are however available from the authors upon reasonable request and with permission of the Xinjiang Medical University Affiliated Hospital of Traditional Chinese Medicine.

\section{Ethics approval and consent to participate}

The study protocol was approved by the ethics committee of the Xinjiang Medical University Affiliated Hospital of Traditional Chinese Medicine. Because of the retrospective design of the study, the need to obtain informed consent.From eligible patients was waived by the ethics committee.

\section{Consent for publication}

Not applicable.

\section{Competing interests}

The authors declare that they have no conflict of interests.

\section{Author details}

${ }^{1}$ Department of Cardiology Fourth Ward, The Xinjiang Medical University Affiliated Hospital of Traditional Chinese Medicine, Urumqi 830011, China.

${ }^{2}$ The People's Hospital of Xuancheng City, Anhui 242000, China.

Received: 3 January 2020 Accepted: 8 November 2020

Published online: 30 November 2020

References

1. Ridker PM, Everett Brendan M, Thuren T, et al. Antiinflammatory therapy with canakinumab for atherosclerotic disease. N Engl J Med. 2017;377:1119-31.

2. Goldfine Allison B, Shoelson Steven E. Therapeutic approaches targeting inflammation for diabetes and associated cardiovascular risk. J Clin Invest. 2017;127:83-93.

3. Choi D-H, Kobayashi Y, Nishi T, et al. Combination of mean platelet volume and neutrophil to lymphocyte ratio predicts long-term major adverse cardiovascular events after percutaneous coronary intervention. Angiology. 2019;70:345-51.

4. Everett Brendan M, Pradhan Aruna D, Solomon Daniel H, et al. Rationale and design of the Cardiovascular Inflammation Reduction Trial: a test of the inflammatory hypothesis of atherothrombosis. Am Heart J. 2013;166(199-207):e15.

5. Libby P, Ridker PM, Hansson GK. In-flammation in atherosclerosis: from pathophysiology to practice. J Am Coll Cardiol. 2009;54:2129-38.

6. Jun W, LiJun LX, et al. Mean platelet volume and coronary plaque vulnerability: an optical coherence tomography study in patients with non-STelevation acute coronary syndrome. BMC Cardiovasc Disord. 2019;19:128.

7. Khot UN, Khot MB, Bajzer CT, et al. Prevalence of conventional risk factors in patients with coronary heart disease. JAMA. 2003;290:898-904.

8. Greenland P, Knoll MD, Stamler J, Neaton JD, Dyer AR, Garside DB, Wilson PW. Major risk factors as antecedents of fatal and nonfatal coronary heart disease events. JAMA.2003; 290: 891-897.

9. Libby P, Ridker PM, Maseri A. Inflammation and atherosclerosis. Circulation. 2002;105(9):1135-43.

10. Rajagopal V, Gurm HS, Bhatt DL, et al. Relation of an elevated white blood cell count after percutaneous coronary intervention to long-term mortality. Am J Cardiol. 2004;94:190-2.

11. Barron H, Harr S, Radford M, et al. The association between white blood cell count and acute myocardial infarction mortality in patients $>$ or $=65$ years of age: Findings from the cooperative cardiovascular project. J Am Coll Cardiol. 2001;38(6):1654-61.

12. Zouridakis EG, Garcia-Moll X, Kaski JC. Usefulness of the blood lymphocyte count in predicting recurrent instability and death in patients with unstable angina pectoris. Am J Cardiol. 2000;86:449-51.

13. Liu JF, Ba L, Lv H, et al. Association between neutrophil-to-lymphocyte ratio and differentiated thyroid cancer: a meta-analysis. Sci Rep. 2016:6:38551. 
14. Huankun $S$, Jiaqun $Q$, Yangpei $P$, et al. The neutrophil-lymphocyte ratio: a promising predictor of mortality in coronary care unit patients - a cohort study. Int Immunopharmacol. 2019;74:105692.

15. Na Xu, Xiao-Fang T, Yi Y, et al. Predictive value of neutrophil to lymphocyte ratio in long-term outcomes of left main and/or three-vessel disease in patients with acute myocardial infarction. Catheter Cardiovasc Interv. 2018:91:551-7.

16. Kaya A, Kurt M, Tanboga $\mathrm{H}$, et al. Relation of neutrophil to lymphocyte ratio with the presence and severity of stable coronary artery disease. Clin Appl Thromb Hemost. 2014;20:473-7.

17. Kurtul S, Sarli B, Baktir AO, et al. Neutrophil to lymphocyte ratio predicts SYNTAX score in patients with non-ST segment elevation myocardial infarction. Int Heart J. 2015:56:18-21.

18. Kaya H, Ertaş F, Soydinç MS. Association between neutrophil to lymphocyte ratio and severity of coronary artery disease. Clin Appl Thromb Hemost. 2014;20:221.

19. Mendis S, Thygesen K, Koulasmaa K, et a1. Wodd Health Organization definition of myocardial infarction: 2008-09 revision. Int J Epidemiol, 2011, 40(1): 139.146

20. Wang J, Zhang L, Wang F, Liu L, Wang H. China National Survey of Chronic Kidney Disease Working Group. Prevalence, awareness, treatment, and control of hypertension in China: results from a national survey. Am J Hypertens.2014;27:1355-61.

21. Olafsdottir E, Andersson DK, Dedorsson I, Stefey. Am J Hypertens.2014 fretinopathy in subjects with and without type 2 diabetes mellitus. Acta Ophthalmol. 2014;92(2):133-7.

22. Levey AS, Bosch JP, Lewis JB, et al; Modification of Diet in Renal Disease Study Group. A more accurate method to estimate glomerular filtration rate from serum creatinine: a new prediction equation. Ann Intern Med. 1999;130:461-470.

23. Alpert JS. Universal definition of myocardial infarction. Eur Heart J. 2008;29(9):1209.

24. Gensini GG. A more meaningful scoring system for determining the severity of coronary heart disease. Am J Cardiol. 1983;51:606.

25. Sinning C, Zengin E, Waldeyer $C$, et al. SYNTAX score-0 patients: risk stratification in nonobstructive coronary artery disease. Clin Res Cardiol. 2016;105:901-11.

26. Lozano R, Naghavi MK, Foreman K, et al. Global and regional mortality from 235 causes of death for 20 age groups in 1990 and 2010:a systematic analysis for the Global Burden of Disease Study 2010. Lancet. 2012;380(9859):2095-128.
27. Potenza MA, Nacci C, De SMA, et al. Targeting endothelial metaflammation to counteract diabesity cardiovascular risk: Current and perspective therapeutic options. Pharmacol Res. 2017;120:226-41.

28. Sano T, Tanaka A, Namba M, et al. C-reactive protein and lesion morphology in patients with acute myocardial infarction. Circulation. 2003;108:282.

29. Wei P, Deliang Z, Canxiu Z, et al. Application of neutrophil/lymphocyte ratio in predicting coronary blood flow and mortality in patients with ST-elevation myocardial infarction undergoing percutaneous coronary intervention. J Cardiol. 2015;66:9-14.

30. Kim S, Eliot M, Koestler Devin C, et al. Association of Neutrophil-to-Lymphocyte Ratio With Mortality and Cardiovascular Disease in the Jackson Heart Study and Modification by the Duffy Antigen Variant. JAMA Cardiol. 2018;3:455-62.

31. Jala VR, Haribabu B. Leukotrienes and atherosclerosis: new roles for old mediators. Trends Immunol 2004;25:315e22.

32. Fiarresga AJ, Ferreira RC, Feliciano J, et al. Prognostic value of neutrophil response in the era of acute myocardial infarction mechanical reperfusion. Rev Port Cardiol. 2004;23:1387-96.

33. Vakili $\mathrm{H}$, Shirazi M, Charkhkar M, et al. Correlation of platelet-to-lymphocyte ratio and neutrophil-to-lymphocyte ratio with thrombolysis in myocardial infarction frame count in ST-segment elevation myocardial infarction. Eur J Clin Invest. 2017;47:322-7.

34. Akpek M, Kaya MG, Lam YY, et al. Relation of neutrophil/lymphocyte ratio to coronary flow to in-hospital major adverse cardiac events in patients with STelevated myocardial infarction undergoing primary coronary intervention. Am J Cardiol. 2012;110:621-7.

35. Habib H, Sadegh PSM, Najmaldin S. Evaluation of complete blood count parameters in cardiovascular diseases: An early indicator of prognosis? Exp Mol Pathol. 2019;110:104267.

36. Komukai K, Kubo T, Kitabata H, et al. Effect of atorvastatin therapy on fibrous cap thickness in coronary atherosclerotic plaque as assessed by optical coherence tomography: the EASY-FIT study. J Am Coll Cardiol. 2014;64:2207-17.

\section{Publisher's Note}

Springer Nature remains neutral with regard to jurisdictional claims in published maps and institutional affiliations.
Ready to submit your research? Choose BMC and benefit from:

- fast, convenient online submission

- thorough peer review by experienced researchers in your field

- rapid publication on acceptance

- support for research data, including large and complex data types

- gold Open Access which fosters wider collaboration and increased citations

- maximum visibility for your research: over $100 \mathrm{M}$ website views per year

At BMC, research is always in progress.

Learn more biomedcentral.com/submissions 